\title{
Enantioselective ring opening of meso- epoxides by aromatic amines catalyzed by lanthanide iodo binaphtholates
}

Fabien Carrée, Richard Gil, Jacqueline Collin*

Laboratoire de Catalyse Moléculaire, UMR 8075, ICMMO,

Bâtiment 420, Université Paris-Sud, 91405, Orsay, France

jacollin@icmo.u-psud.fr 

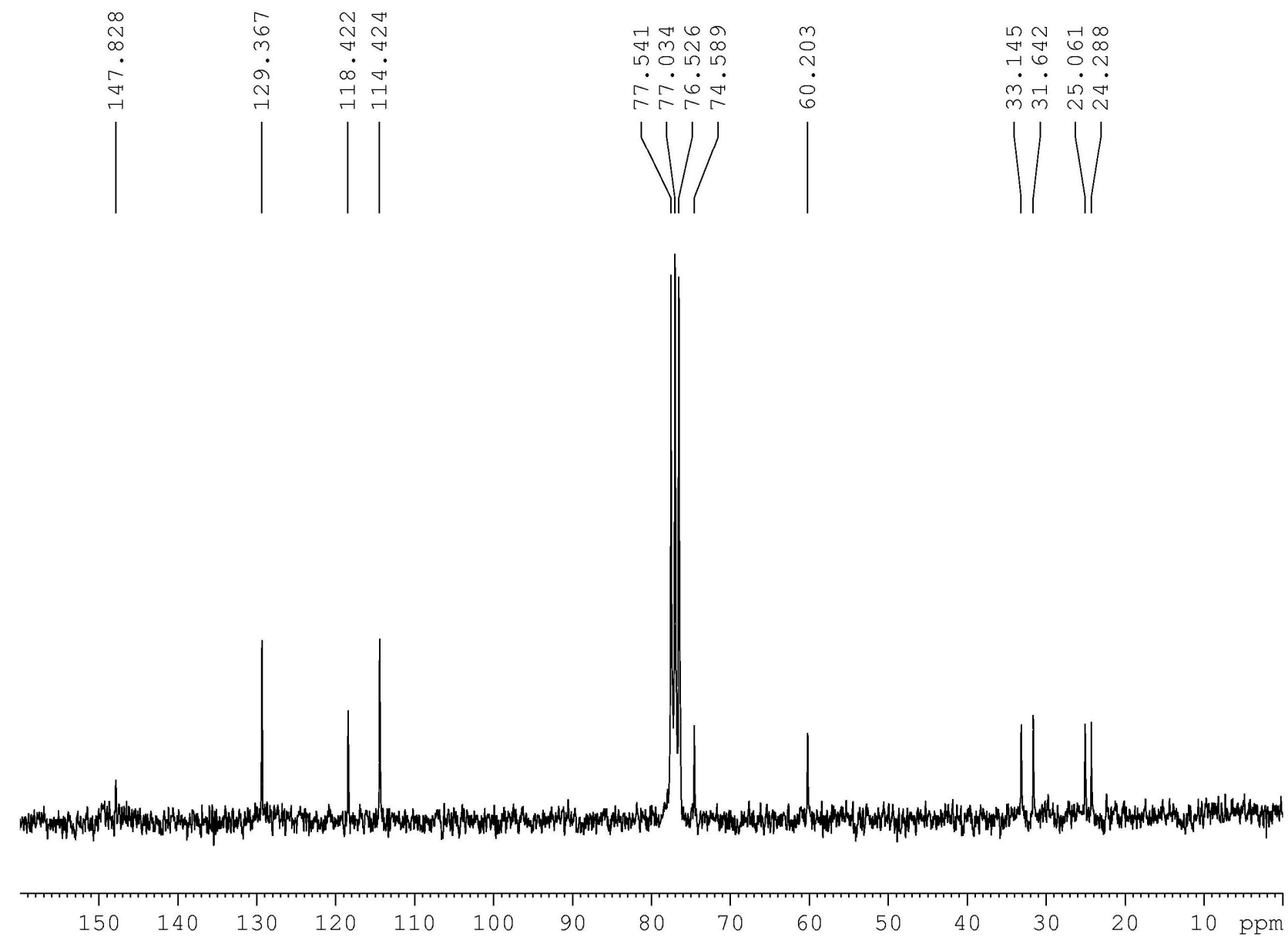


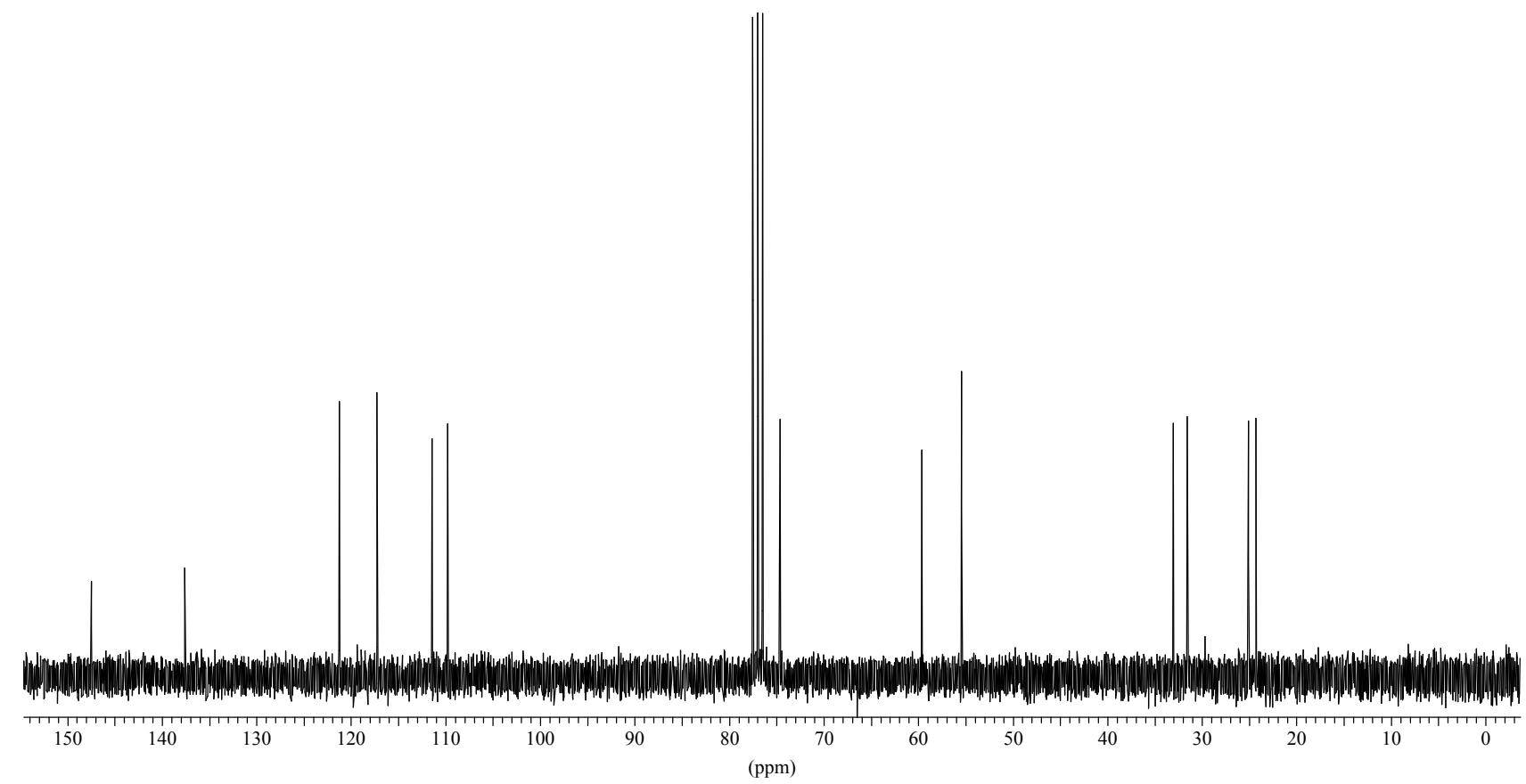




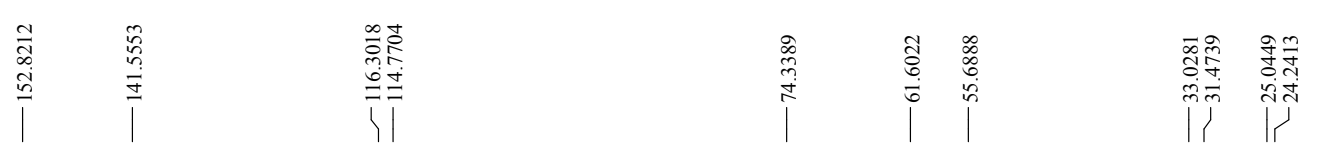

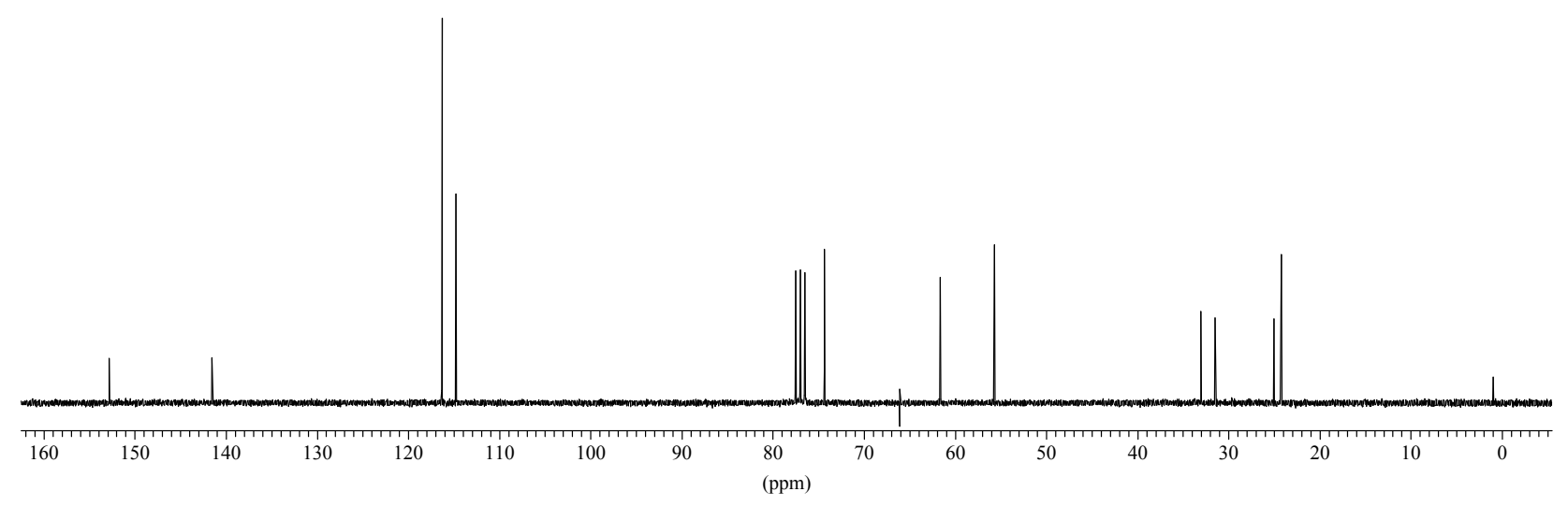


$(1 R, 2 R)$-2-Phenylaminocyclopentanol $\mathbf{4 b - 1}$

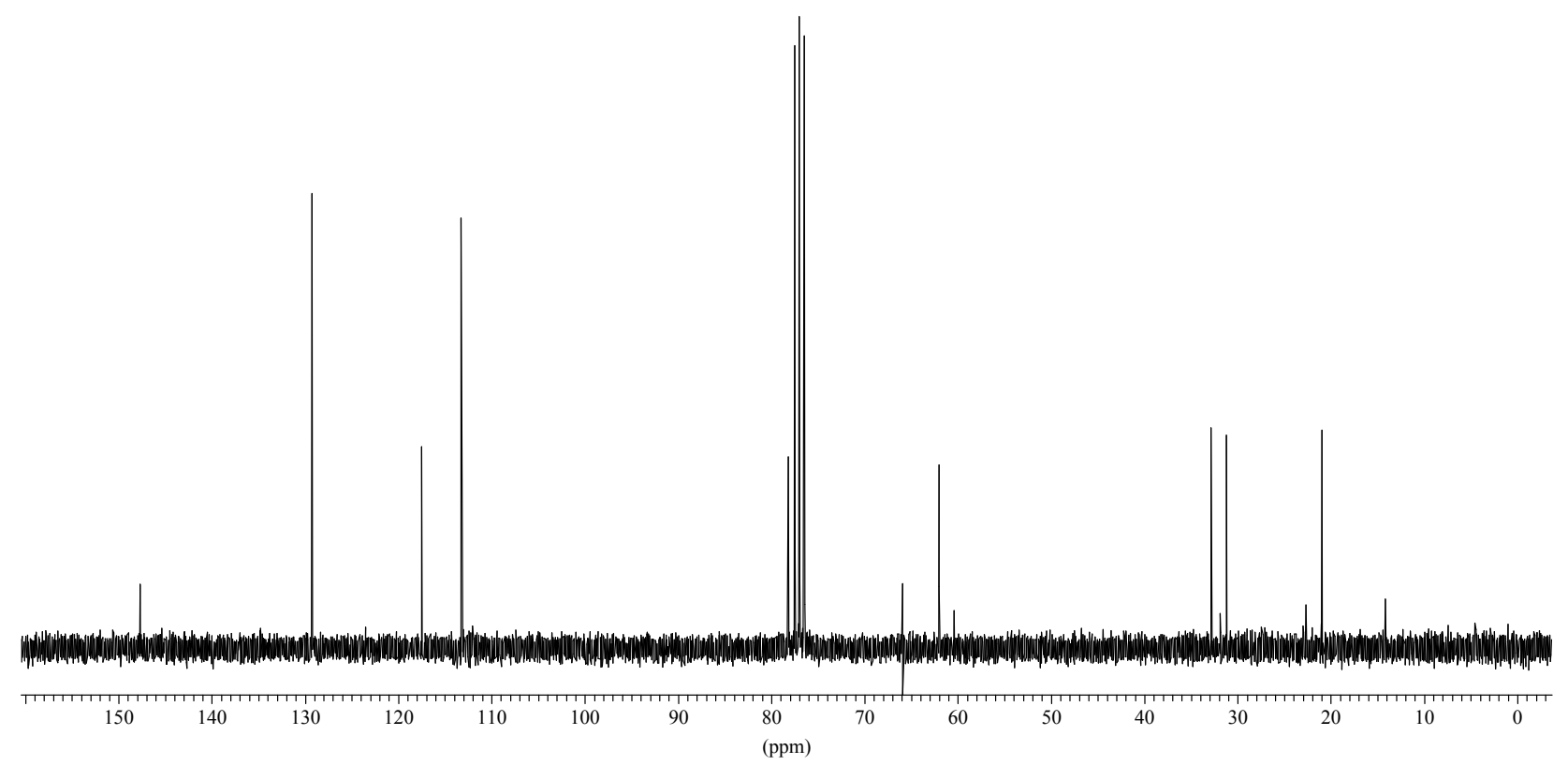


$(1 R, 2 R)-2-(2-M e t h o x y p h e n y l a m i n o)-c y c l o p e n t a n o l ~ \mathbf{4 b - 2}$

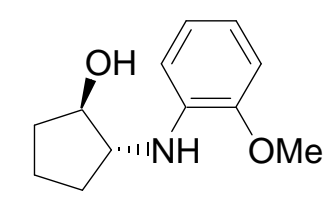

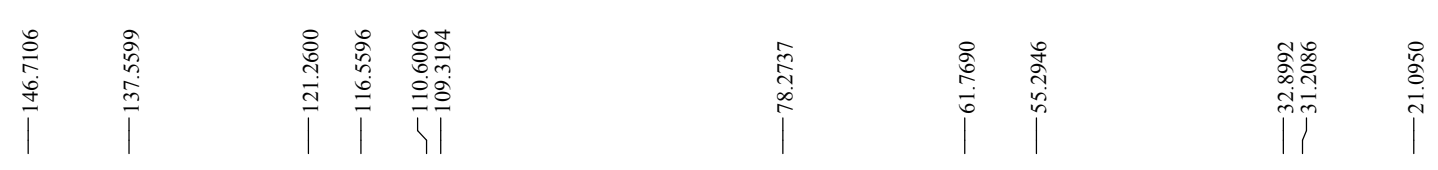

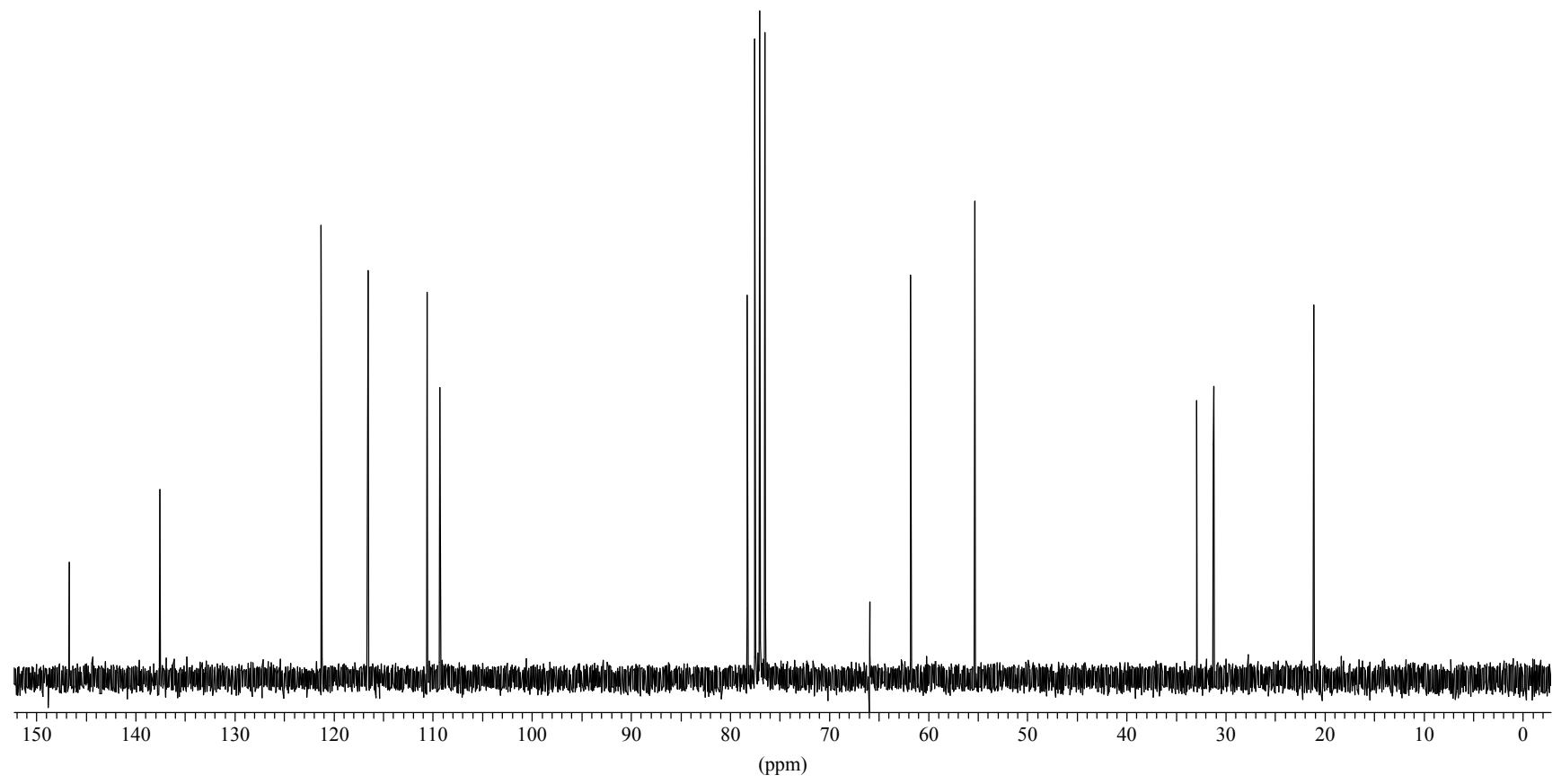




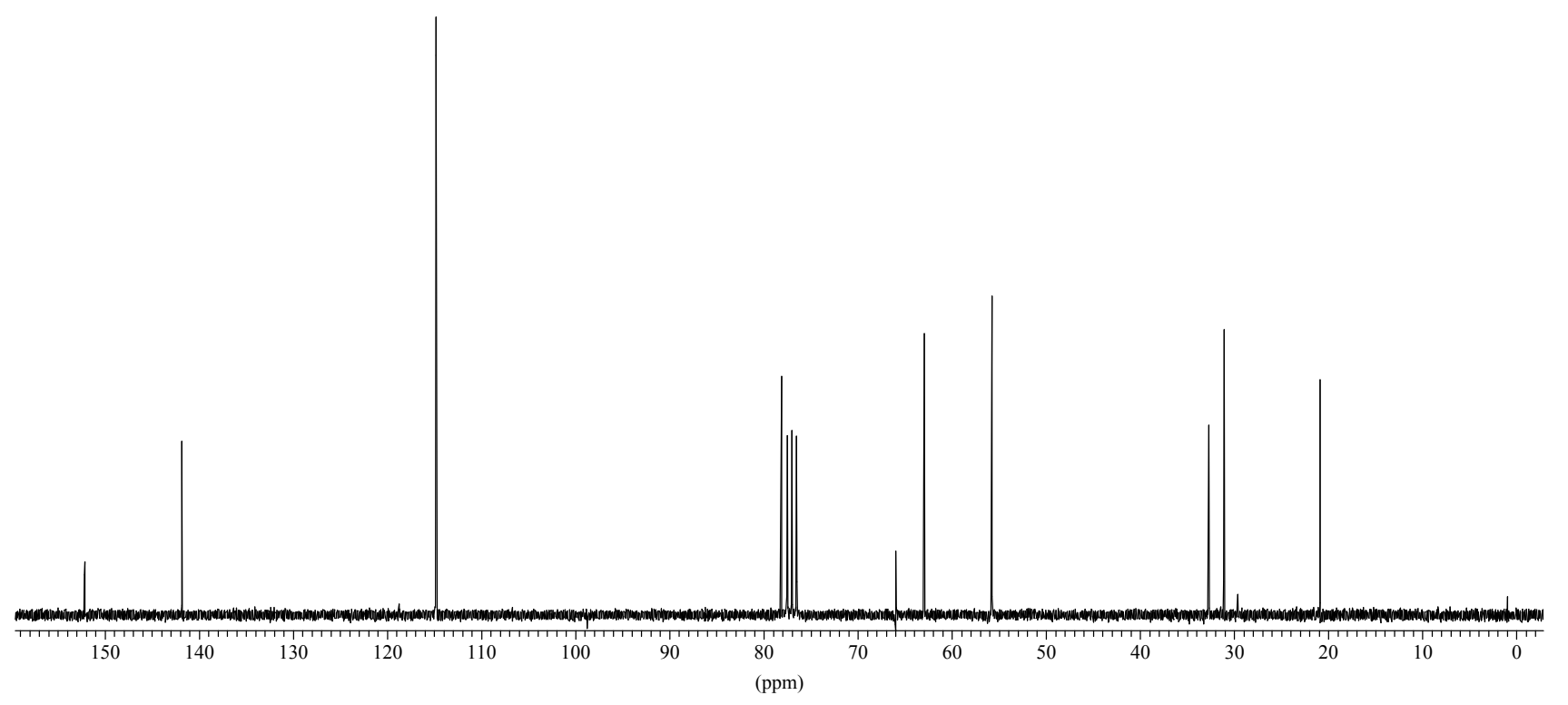




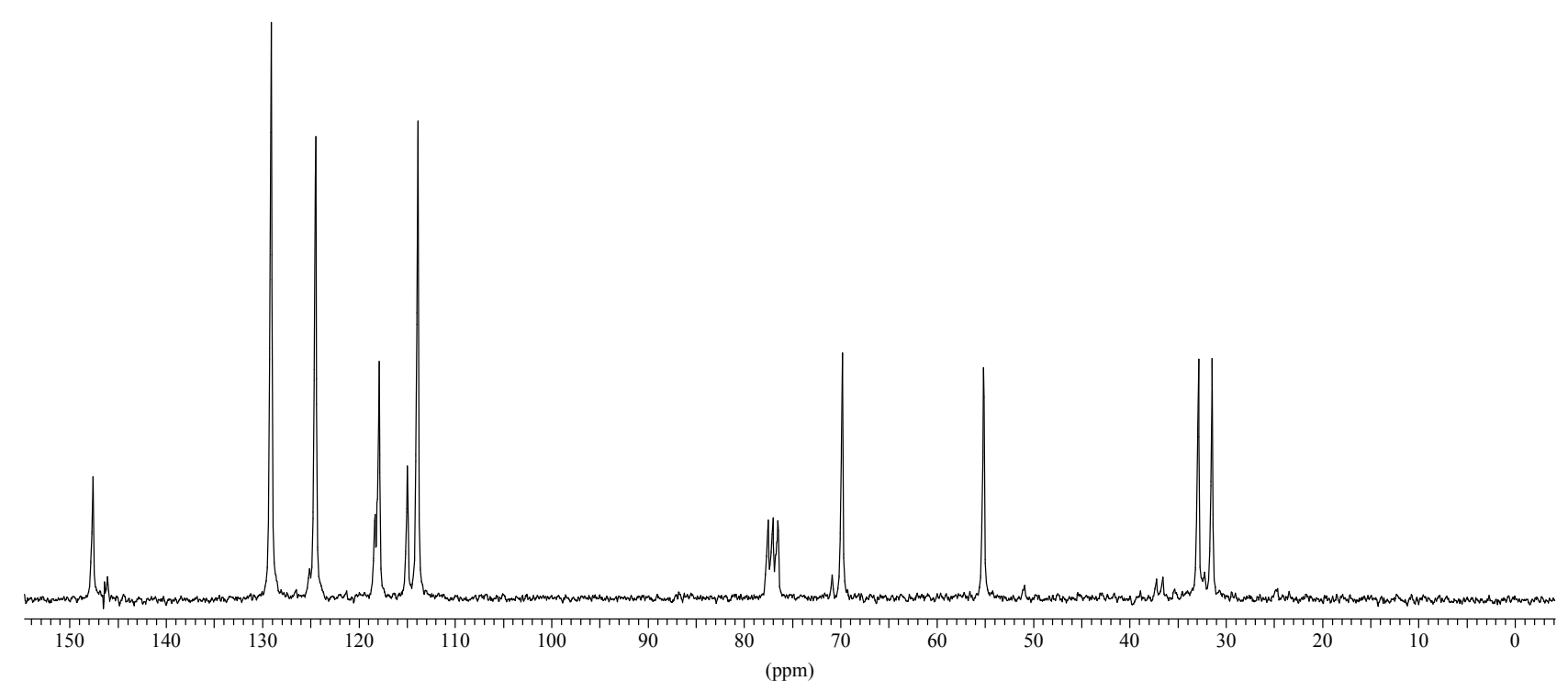




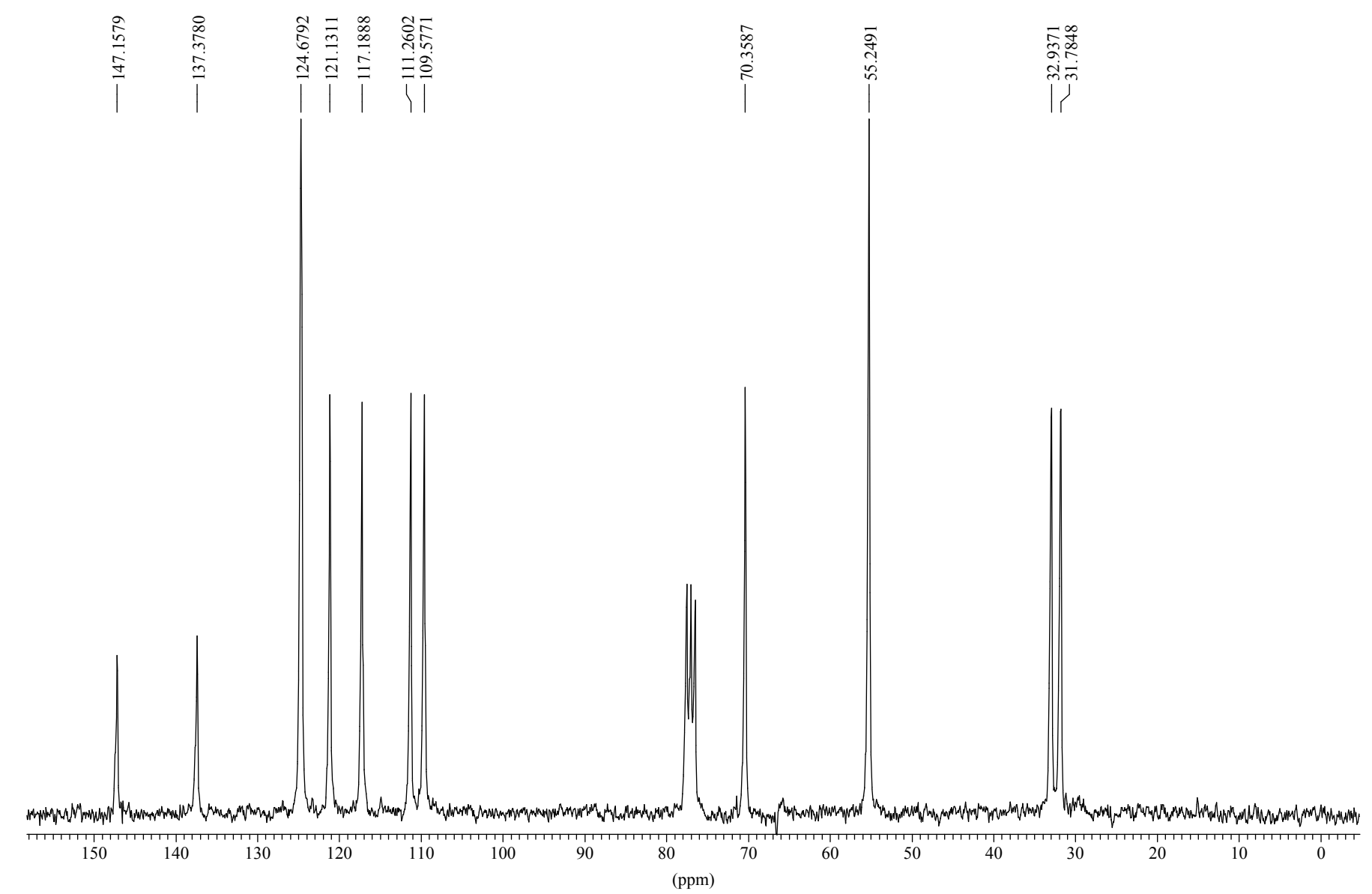




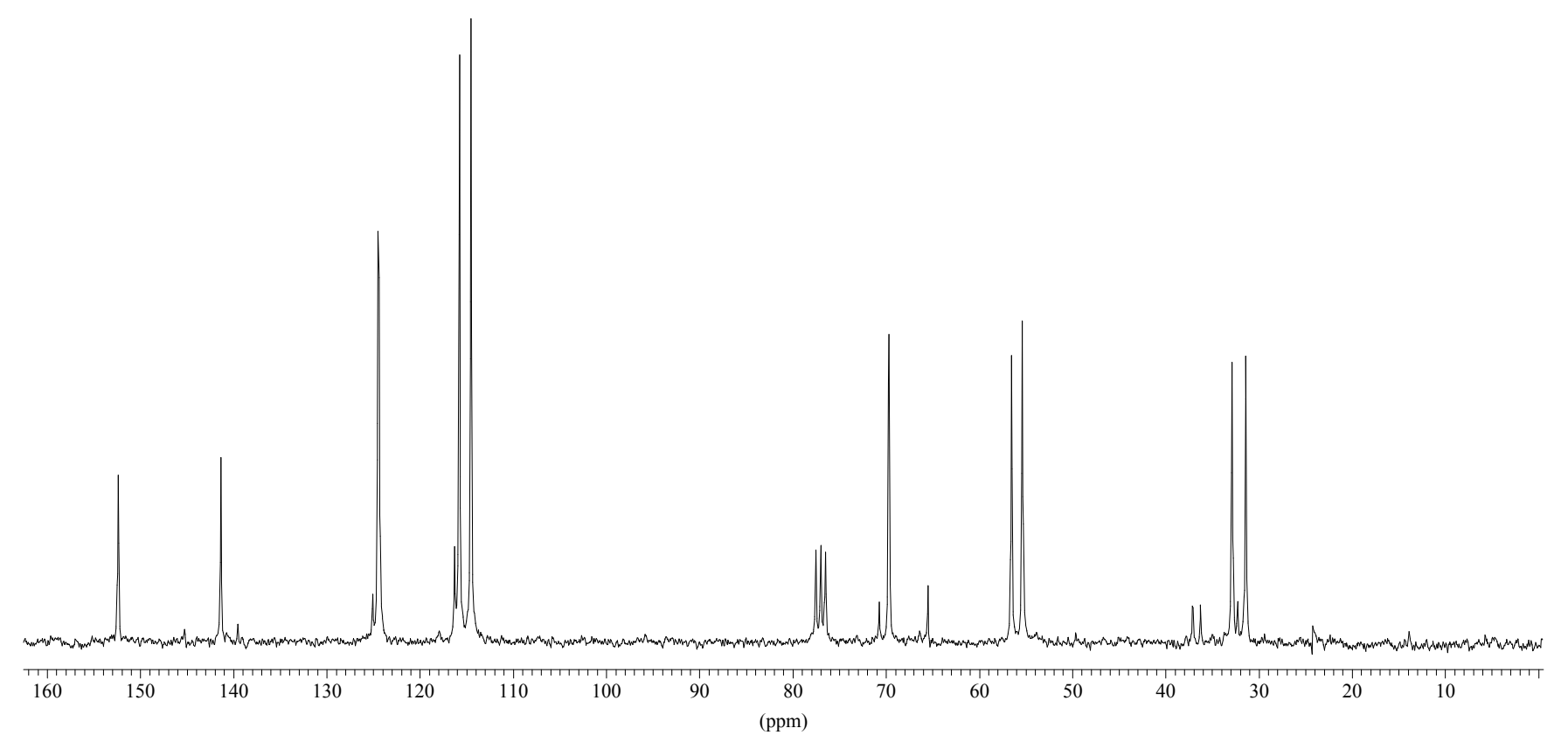




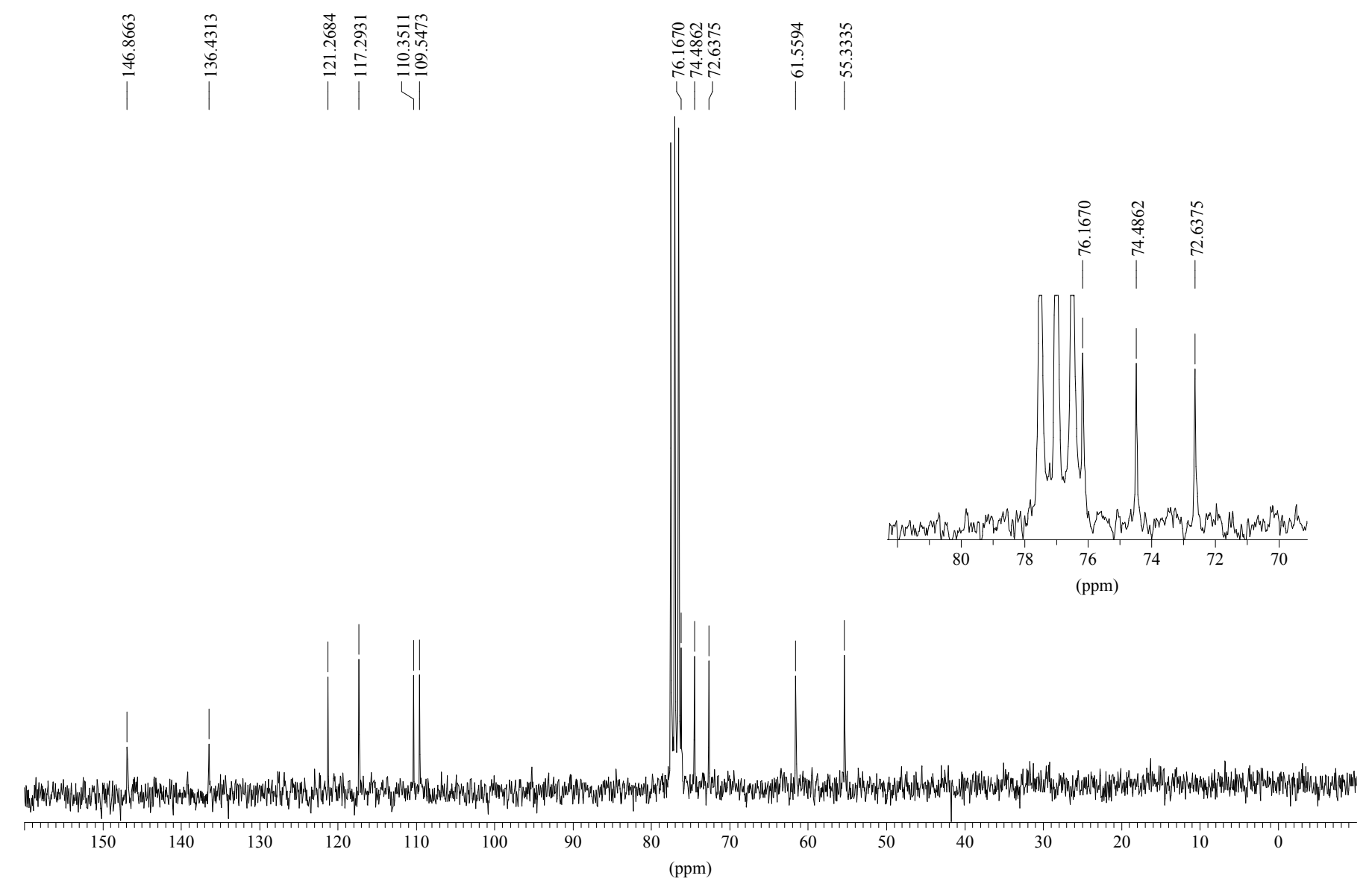

